\title{
Hazardous drinkers in Norwegian hospitals - a cross-sectional study of prevalence and drinking patterns among somatic patients
}

\author{
Kristian Oppedal $^{1,2}$, Sverre Nesvåg ${ }^{1}$, Bolette Pedersen ${ }^{3,4}$, Jan Tore Daltveit ${ }^{2}$ \\ and Hanne Tønnesen ${ }^{3,4}$ \\ 1) Drug and Alcohol Research Western Norway, Stavanger University Hospital \\ 2) Haukeland University Hospital \\ 3) WHO Collaborating Centre, Bispebjerg University Hospital \\ 4) Clinical Alcohol Research, Lund University \\ Correspondence: Kristian Oppedal, E-mail: kiop@sus.no Telephone: +(47) 48124947
}

\begin{abstract}
Background: High alcohol intake has been associated with increased risk of hospital admission, increased complication rates, and prolonged hospital stay. Thus, hospital admission may present a relevant opportunity for alcohol intervention. To understand the potential of alcohol interventions we need knowledge about patients' drinking patterns. The aim of this study was therefore to determine the drinking patterns in a Norwegian hospital population.

Methods: A multicentre cross-sectional survey was carried out at three university hospitals. Patients were asked about alcohol intake one month prior to admission/outpatient treatment. The questionnaire included weekly alcohol intake calculated by frequency $\mathrm{X}$ quantity as well as episodes of binge drinking (drinking more than 5 AU during a single day). AUDIT-C was used to determine the frequency of patients having a hazardous drinking pattern during the 12 months prior to hospital treatment.

Results: In total we assessed 2,932 patients for eligibility. A total of 2,350 patients fulfilled the inclusion criteria. We included 1,522 patients (65\%) in the analyses. Six percent of the women and $11 \%$ of the men reported drinking more than the weekly limits of nine alcohol units (AU) for women and 14 AU for men. Fourteen percent of the women and $29 \%$ of the men reported binge drinking during the last month. The frequency of women scoring more or equal to 4 points on AUDIT-C was $20 \%$. The frequency of men scoring more or equal to 5 points was $25 \%$.

Conclusion: Hazardous drinking among Norwegian hospital patients may be more prevalent than what has been reported for the Norwegian population in general. Binge drinking is the dominant drinking pattern.
\end{abstract}

\section{INTRODUCTION}

Alcohol abuse, including heavy or hazardous drinking, is a major concern internationally, and there is strong evidence that alcohol is a significant threat to world health (1). Alcohol is linked to 1.8 million deaths per annum worldwide, and the global alcohol consumption continues to increase $(2,3)$. The total alcohol consumption per capita in Norway is among the lowest in Europe (4). However, the alcohol consumption per inhabitant aged 15 years or older has steadily increased from 5.45 litres of ethanol in 1999 to 6.75 litres in 2008 (4). It has been estimated that an unregistered consumption representing $25-30 \%$ of the total alcohol consumption (4) adds to these numbers.

Alcohol adversely affects several organ systems, including the liver, pancreas, and nervous system (5). A high weekly alcohol intake is associated with an increased risk of hospital admission due to stroke, liver disease, and respiratory diseases $(6,7)$, as well as increased complication rates and a prolonged hospital stay after surgery (8). Hospitals may therefore be a relevant setting for alcohol interventions, but the agenda is complex. While some interventions aim for increased quality of patient care with respect to the current disease (9) others are opportunistic and aim to identify and intervene with regard to patients at risk for future or long term alcohol-related co-morbitiy and dependence (10). Furthermore, whilst some hospital patients are admitted with alcohol-related diseases or injuries, which may be acute or chronic, others may exhibit indicators of a current hazardous alcohol intake without present alcohol-related morbidity. Both groups are relevant target groups for alcohol interventions.

Understanding the potential of different alcohol interventions for hospital patients requires data not only on the effect of alcohol interventions, but also on the prevalence of patients who may benefit from them. The aim of this study was therefore to determine the drinking patterns in a Norwegian hospital population.

\section{MATERIAL AND METHODS}

A multicentre cross-sectional survey was carried out at all non-psychiatric wards and outpatient clinics at Haukeland University Hospital, Stavanger University 
Table 1. Items and scores concerning alcohol use. All items were included in the structured questionnaire.

\begin{tabular}{|c|c|c|}
\hline \multicolumn{2}{|l|}{ Items } & Score \\
\hline \multicolumn{3}{|l|}{ Weekly alcohol consumption } \\
\hline \multicolumn{2}{|l|}{ Number of drinking days per week during the previous month } & Number of days \\
\hline \multicolumn{2}{|c|}{ Number of drinks ${ }^{\mathrm{a}}$ consumed on a typical drinking day during the previous month } & Number of drinks \\
\hline \multicolumn{2}{|c|}{ Binge drinking: Number of days drinking more than five drinks ${ }^{\mathrm{a}}$ during the previous month } & Number of days \\
\hline Alcohol Use Disorder Identification Test - C (AUDIT-C)Items & Alternatives & Points \\
\hline \multirow{5}{*}{$\begin{array}{l}\text { How often did you have a drink }{ }^{\mathrm{a}} \text { containing alcohol during } \\
\text { the last year? }\end{array}$} & Never & 0 \\
\hline & Monthly or less & 1 \\
\hline & Two to four times a month & 2 \\
\hline & Two to three times per week & 3 \\
\hline & Four or more times a week & 4 \\
\hline \multirow{5}{*}{$\begin{array}{l}\text { How many drinks }{ }^{\mathrm{a}} \text { containing alcohol did you have on a } \\
\text { typical day when you were drinking during the last year? }\end{array}$} & Up to 2 & 0 \\
\hline & 3 or 4 & 1 \\
\hline & 5 or 6 & 2 \\
\hline & 7 to 9 & 3 \\
\hline & 10 or more & 4 \\
\hline \multirow{5}{*}{$\begin{array}{l}\text { How often did you have six or more drinks }{ }^{\mathrm{a}} \text { on one occasion } \\
\text { during the last year? }\end{array}$} & Never & 0 \\
\hline & Less than monthly & 1 \\
\hline & Monthly & 2 \\
\hline & Weekly & 3 \\
\hline & Daily or almost daily & 4 \\
\hline
\end{tabular}

${ }^{\mathrm{a} O n e}$ drink equals to 12 grams of ethanol

Hospital, and Haraldsplass Deaconess Hospital, with the exception of intensive care units and paediatrics departments. These hospitals serve approximately one million inhabitants in the western region of Norway, and they comprise 80 wards and 49 outpatient clinics. Inclusion took place during a 24-h assessment period in April 2009, and did not include the weekend. Due to organisational issues, five wards and four outpatient clinics did not wish to take part in the study.

\section{Sample}

The inclusion criteria were: being admitted or treated at an outpatient clinic, being at least 18 years old, and giving informed consent to participate. The exclusion criteria were: reduced ability or lack of competence to provide consent, and inability to answer the questions in Norwegian due to inadequate language skills.

\section{Interviews}

In total, 350 specifically trained nursing students interviewed the patients using a structured questionnaire and registered demographic data including age, sex, and the clinic at which the patient was treated. The questionnaire was presented as one regarding lifestyle and nutrition, and comprised 13 questions. Three questions covered drinking patterns during the previous month. The questions concerned quantity and frequency of alcohol consumption as well as frequency of binge drinking episodes. The AUDIT-C questionnaire (11, 12) was used to assess drinking patterns during the previous year. Table 1 shows the items of the questionnaire concerning alcohol intake.

\section{Measurements}

High weekly alcohol consumption, monthly binge drinking and/or high AUDIT-C scores defined hazardous drinking. The average weekly alcohol consumption was calculated by multiplying the number of alcohol units $(A U)$ consumed during a normal drinking day by the number of drinking days in a normal week. One AU contained 12 grams of pure ethanol. The weekly drinking limits were defined by a cut-off of more than or equal to nine $\mathrm{AU}$ per week for women and more than or equal to $14 \mathrm{AU}$ per week for men. This corresponds to internationally recognised guidelines for "sensible" alcohol consumption (13-15). Binge drinking was defined as an alcohol intake of $5 \mathrm{AU}$ or more during a single day (16). AUDIT-C scores were calculated based on the three questions, where the minimum score is 0 and the maximum score is 12 . AUDIT-C cut-offs of 4 points were used for women, and 5 points were used for men $(17,18)$.

Finally, twenty random patient interviews were recorded and transcribed. Each interview was then assessed by 20 nursing students regarding the patients' drinking patterns. The students were randomly drawn from a list and they scored each interview independently.

\section{Statistics}

Frequencies were calculated for the patients exceeding the weekly limits, for binge drinkers and for patients with positive AUDIT-C scores. Subgroup analysis was performed for men and women, inpatients and outpatients, as well as for departments at which the patients received treatment. 


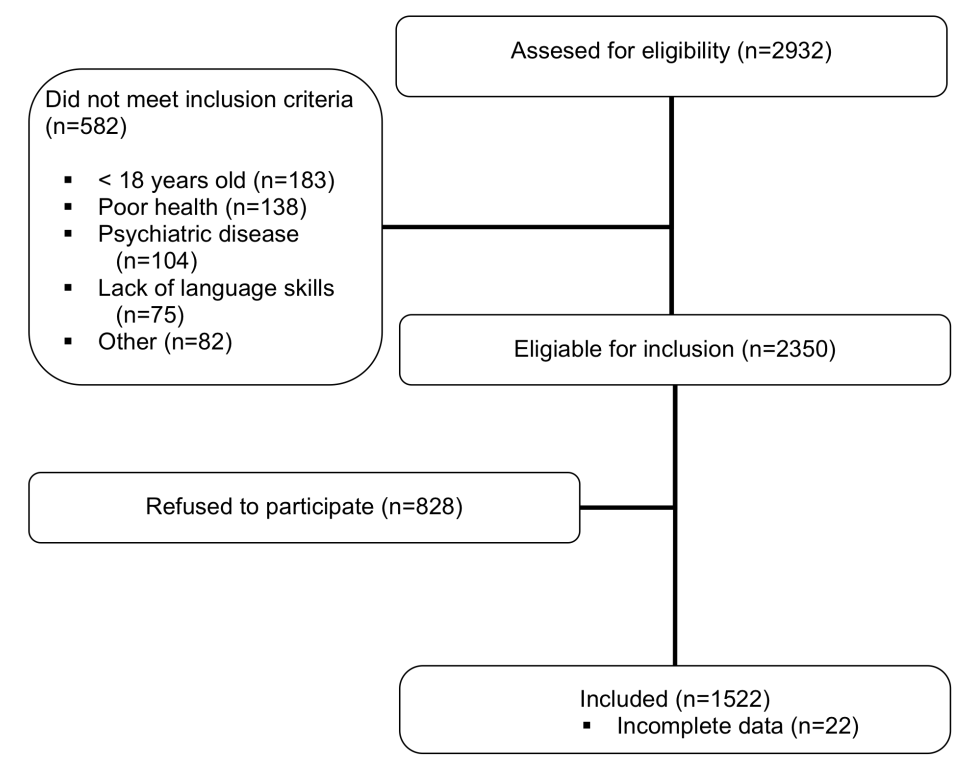

Figure 1. Study profile, showing the number of eligible and included patients. Inclusion rate was $65 \%$. 22 questionnaires were incomplete.

Kappa statistics (multirater version) was used to describe the median interrater reliability among the 20 students for weekly alcohol consumption, binge drinking and AUDIT-C scores in the 20 interviews that they had assessed. A kappa of 0.7 or higher indicated adequate interrater agreement. CI values were also calculated for each kappa statistic. Analyses were carried out using SPSS 17.0.

\section{Ethics}

The study protocol was in accordance with the Declaration of Helsinki II and was approved by the Regional Committee for Medical Research Ethics for Western Norway (no. 2009/106-ØYSV) and the Norwegian Social Science Data Services (no. 20985). Informed consent was obtained from all study participants.

\section{RESULTS}

In total we assessed 2,932 patients for eligibility. A total of 2,350 patients fulfilled the inclusion criteria. We included 1,522 patients $(65 \%)$ in the analyses. Reasons reported by non-responders included lack of time, inappropriate timing, and poor health. Partly incomplete information was registered in 22 questionnaires (see figure 1 for study profile). We excluded patients with incomplete data from analyses where missing data were required.

Forty-six percent of the included patients were women. The median age was 60 years (range 18-95 years), with women being slightly but not significantly $(p=0.063, t$-test) older than men (62 years versus 60 years).

\section{Hazardous drinking patterns}

Of the total population, $31 \%$ fulfilled one or more than one of the criteria for hazardous drinking. Six percent of the women and $11 \%$ of the men reported drinking more or equal to the weekly limits of nine AU for women and $14 \mathrm{AU}$ for men. Fourteen percent of the women and $29 \%$ of the men reported binge drinking during the last month. The frequency of women scoring more or equal to 4 points on AUDIT-C was $20 \%$. The frequency of men scoring more or equal to 5 points was $25 \%$. Table 2 shows a summary of findings.

Figure 2 shows a Venn diagram of how drinking patterns overlapped among the 471 patients who fulfilled at least one of the criteria for hazardous drinking. Binge drinking which also is an item in AUDIT-C was the dominant drinking pattern.

\section{Department types}

The frequencies of hazardous drinkers were highest in departments of surgery; dermatology; and ear, nose and throat (ENT), and lowest in departments of oncology and obstetrics/gynaecology (Table 2).

\section{Interrater reliability}

The interrater reliability was more than adequate for all drinking patterns: 0.90 (CI 0.81-1.00) for drinking more than the weekly limits $(\geq 9$ (w)/14 (m) AU per week), 0.90 (CI 0.78-1.00) for binge drinking and 0.91 (CI 0.77-1.00) for positive AUDIT-C scores.

\section{DiscuSSION}

This study is the first to report the prevalence of hazardous drinkers and drinking patterns in a Norwegian hospital population.

While less than one tenth of the population reported having a high weekly alcohol consumption one month prior to hospital treatment one fifth reported binge drinking in the same period. Hazardous drinking patterns were more common among males than among 
Table 2. Hazardous drinkers shown as percentages of subgroups meeting different criteria for hazardous drinking.

\begin{tabular}{|c|c|c|c|}
\hline & $\begin{array}{c}\geq 9\left(\mathrm{w}^{\mathrm{a}}\right) / 14\left(\mathrm{~m}^{\mathrm{b}}\right) \\
\mathrm{AU}^{\mathrm{c}} / \text { week } \\
\%(\mathrm{n})\end{array}$ & $\begin{array}{c}\text { Binge drinking } \\
>1 \text { day/month } \\
\%(\mathrm{n})\end{array}$ & $\begin{array}{c}\text { AUDIT-C } \geq 4 \\
\left(\mathrm{w}^{\mathrm{b}}\right) / 5\left(\mathrm{~m}^{\mathrm{c}}\right) \\
\%(\mathrm{n})\end{array}$ \\
\hline \multicolumn{4}{|l|}{ Sex } \\
\hline Men & $11(90)$ & 29 (237) & $25(201)$ \\
\hline Women & $6(39)$ & $14(97)$ & $21(148)$ \\
\hline \multicolumn{4}{|l|}{ Setting } \\
\hline Inpatients & $6(47)$ & $18(128)$ & $19(135)$ \\
\hline Outpatients & $10(79)$ & 25 (196) & $27(208)$ \\
\hline Unknown $\mathrm{n}=31$ & $10(3)$ & $32(10)$ & $19(6)$ \\
\hline \multicolumn{4}{|l|}{ Department } \\
\hline General surgery & $13(40)$ & $26(80)$ & $26(83)$ \\
\hline Orthopaedic surgery & $8(9)$ & $21(25)$ & $22(26)$ \\
\hline Internal medicine & $6(27)$ & $20(89)$ & $21(91)$ \\
\hline $\mathrm{Ob} / \mathrm{Gyn}^{\mathrm{d}}$ & $8(5)$ & $10(6)$ & $19(12)$ \\
\hline Dermatology & $12(8)$ & $31(21)$ & $31(20)$ \\
\hline Ophthalmology & $4(3)$ & $14(12)$ & $18(15)$ \\
\hline $\mathrm{ENT}^{\mathrm{e}}$ & $11(12)$ & $35(39)$ & $28(31)$ \\
\hline Neurology & $10(8)$ & $20(17)$ & $20(17)$ \\
\hline Oncology & $4(5)$ & $13(17)$ & $21(26)$ \\
\hline Emergency room & $10(9)$ & $19(18)$ & $24(22)$ \\
\hline Unknown $\mathrm{n}=31$ & $10(3)$ & $32(10)$ & $19(6)$ \\
\hline
\end{tabular}

${ }^{\mathrm{a}}$ Women
${ }^{\mathrm{b}}$ Men
${ }^{\mathrm{c}}$ Alcohol unit
${ }^{\mathrm{d}}$ Obstetrics/gynaecology
${ }^{\mathrm{e}}$ Ear, nose and throat

${ }^{\mathrm{e}}$ Ear, nose and throat

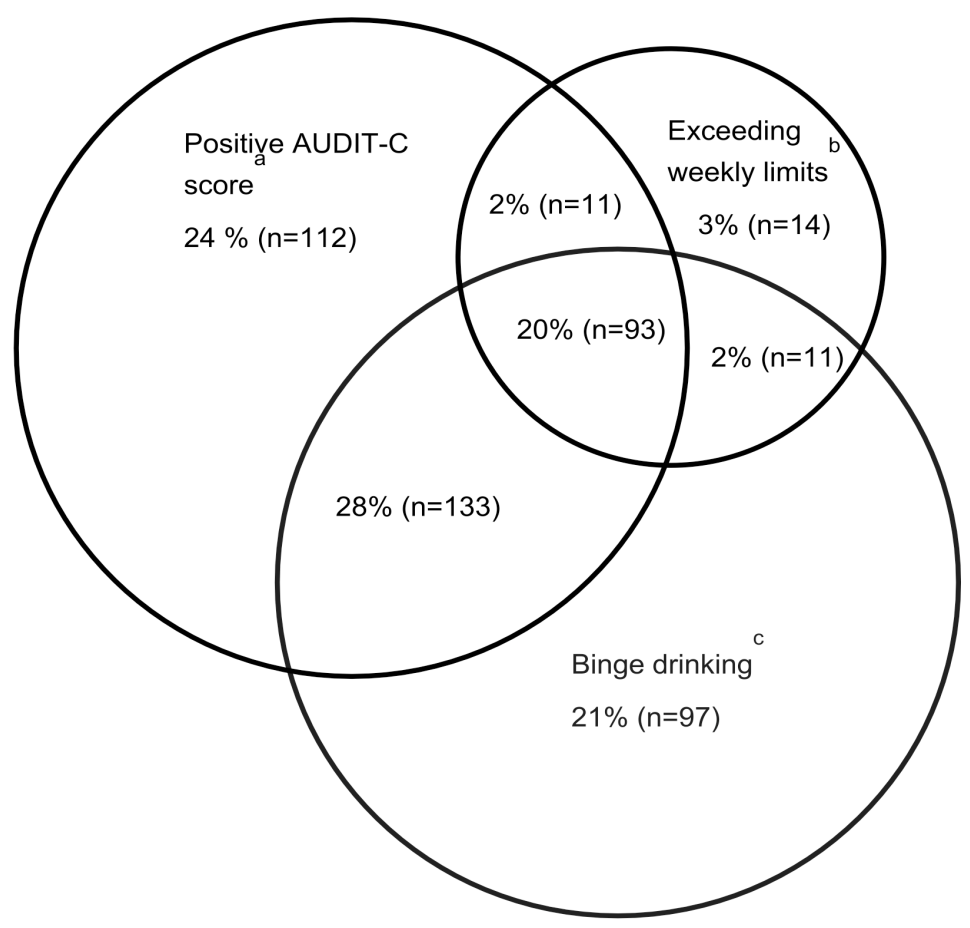

Figure 2. Venn diagram showing overlap of hazardous drinking patterns among 471 hazardous drinkers. The diagram is not to scale.

${ }^{\text {a }}$ Positive AUDIT-C score; $\geq 4$ points for women, and $\geq 5$ points for men.

${ }^{\mathrm{b}}$ Exceeding the weekly limits; $\geq 9$ alcohol units (AU) per week for women and 14 AU per week for men (1 AU $=12$ grams of ethanol).

${ }^{\mathrm{c}}$ Binge drinking; alcohol intake of $5 \mathrm{AU}$ or more during a single day. 
females. This is consistent with other studies $(19,20)$.

One-fifth of the women and one-fourth of the men scored positively on AUDIT-C. These numbers were reflected by the binge drinking pattern.

The obtained results may suggest that the prevalence of hazardous drinkers is higher within Norwegian hospitals than in the Norwegian populations in general, though these numbers generally describe alcohol consumption per capita and not hazardous drinkers per se (21-23). Therefore, reliable inter-study comparisons are not possible due to the large methodological diversity of studies.

There is strong evidence that hospital patients should be asked about alcohol use. Decisions about how to screen for alcohol use in hospitals are complicated by various clinical factors, including the aims and the target groups of interventions. It is well known that the volume of alcohol consumed over certain time periods exerts causal effects on the outcomes of many diseases (both chronic and acute) and injuries (5). It is also likely that disease outcomes are influenced by actual drinking patterns, especially episodes of heavy drinking (5). For secondary preventive interventions recent alcohol intake may be considered clinically relevant as many patophysiological mechanisms are reversed after a short period of abstinence (8). For primary interventions and interventions aiming to reduce alcohol consumption on a longer term, the drinking history of the past year may be just as relevant (10). In our study, a large number of patients were identified as hazardous drinkers due to their drinking pattern rather than due to the volume of alcohol consumed per week. This emphasises the importance of asking patients about binge drinking when this is clinically relevant.
One strength of this study is that it involved a fairly large sample of patients in hospitals of various sizes. We covered all specialities except paediatric wards and intensive care units. Another strength is the high reliability rate among the nursing students. The response rate was $65 \%$, which is less than optimal but comparable to other cross-sectional studies performed at population level (24). It is possible that the patients who declined to participate, and the eligible patients who were excluded, may represent a particular drinking pattern, and that their prevalence and distribution will not be reflected in our numbers. There is also a risk of selection bias because the 24-h assessment period did not include the weekend, when alcohol-attributed admissions presumably are higher. The content of the questions may also have contributed to selection bias, as hazardous drinkers may have been reluctant to participate because they may have been concerned about being identified. We attempted to avoid this by not focusing on alcohol alone and including other healthdeterminants in the survey. Our numbers should probably be interpreted as minimum numbers.

In conclusion hazardous drinking in this Norwegian hospital population may be more prevalent than what has been reported for the Norwegian population in general. Binge drinking was the most frequent drinking pattern. Considering the high prevalence of hazardous drinkers, hospital admission seems to be a good and clinically relevant opportunity for identifying patients eligible for alcohol interventions. More knowledge about how drinking patterns influence clinical outcomes and how screening procedures relate to intervention methods is needed to determine how best to identify patients suitable for alcohol interventions in different hospital settings.

\section{REFERENCES}

1. World Health Organization. A summary of Global Status Report on Alcohol. Geneva: Management of Substance Dependence, Non-Communicable Diseases, World Health Organization, 2001.

2. World Health Organization - Regional office for Europe. Handbook for action to reduce alcohol-related harm. Copenhagen, Denmark: World Health Organization, 2009.

3. Rehm J, Mathers C, Popova S, Thavorncharoensap M, Teerawattananon Y, Patra J. Global burden of disease and injury and economic cost attributable to alcohol use and alcohol-use disorders. Lancet 2009; 373 (9682): 2223-2233.

4. SIRUS - Norwegian Institute for Alcohol and Drug Research. Alcohol and Drugs in Norway 2009. Oslo: SIRUS - Norwegian Institute for Alcohol and Drug Research, 2009.

5. Rehm J, Baliunas D, Borges GL, Graham K, Irving H, Kehoe T, et al. The relation between different dimensions of alcohol consumption and burden of disease: an overview. Addiction 2010; 105 (5): 817-843.

6. Hart CL, Smith GD. Alcohol consumption and mortality and hospital admissions in men from the Midspan collaborative cohort study. Addiction 2008; 103 (12): 1979-1986.

7. McDonald SA, Hutchinson SJ, Bird SM, Graham L, Robertson C, Mills PR, et al. Association of self-reported alcohol use and hospitalization for an alcohol-related cause in Scotland: a record-linkage study of 23,183 individuals. Addiction 2009; 104 (4): 593-602.

8. Tonnesen H, Nielsen PR, Lauritzen JB, Moller AM. Smoking and alcohol intervention before surgery: evidence for best practice. Br J Anaesth 2009; 102 (3): 297-306.

9. Shourie S, Conigrave KM, Proude EM, Ward JE, Wutzke SE, Haber PS. The effectiveness of a tailored intervention for excessive alcohol consumption prior to elective surgery. Alcohol Alcohol 2006; 41 (6): 643-649. 
10. McQueen J, Howe TE, Allan L, Mains D. Brief interventions for heavy alcohol users admitted to general hospital wards. Cochrane Database Syst Rev 2009 (3): CD005191.

11. Bush K, Kivlahan DR, McDonell MB, Fihn SD, Bradley KA. The AUDIT alcohol consumption questions (AUDIT-C): an effective brief screening test for problem drinking. Ambulatory Care Quality Improvement Project (ACQUIP). Alcohol Use Disorders Identification Test. Arch Intern Med 1998; 158 (16): 1789-1795.

12. Bradley KA, McDonell MB, Bush K, Kivlahan DR, Diehr P, Fihn SD. The AUDIT alcohol consumption questions: reliability, validity, and responsiveness to change in older male primary care patients. Alcohol Clin Exp Res 1998; 22 (8): 1842-1849.

13. Batty GD, Lewars H, Emslie C, Gale CR, Hunt K. Internationally recognized guidelines for 'sensible' alcohol consumption: is exceeding them actually detrimental to health and social circumstances? Evidence from a population-based cohort study. J Public Health 2009; 31 (3): 360-365.

14. Andreasson S, Allebeck P. [Alcohol as medication is no good. More risks than benefits according to a survey of current knowledge]. Läkartidningen 2005; 102 (9): 632-637.

15. Department of Health; University of London. St George's. Division of Mental Health. Section of Addictive Behaviour; Kable Limited; MORI Social Research Institute. Alcohol Needs Assessment Research Project (ANARP): The 2004 national alcohol needs assessment for England: Department of Health, 2005.

16. Deutsche Hauptstelle für Suchtfragen e.V. (DHS). Binge Drinking and Europe. Hamm: DHS, 2008.

17. Nordqvist C, Johansson K, Bendtsen P. Routine screening for risky alcohol consumption at an emergency department using the AUDIT-C questionnaire. Drug Alcohol Depend 2004; 74 (1): 71-75.

18. Gual A, Segura L, Contel M, Heather N, Colom J. Audit-3 and audit-4: effectiveness of two short forms of the alcohol use disorders identification test. Alcohol Alcohol 2002; 37 (6): 591-596.

19. Nielsen SD, Storgaard H, Moesgaard F, Gluud C. Prevalence of alcohol problems among adult somatic inpatients of a Copenhagen hospital. Alcohol Alcohol 1994; 29 (5): 583-590.

20. Delgado-Rodriguez M, Gomez-Ortega A, Mariscal-Ortiz M, Palma-Perez S, Sillero-Arenas M. Alcohol drinking as a predictor of intensive care and hospital mortality in general surgery: a prospective study. Addiction 2003; 98 (5): 611-616.

21. Blå Kors Norge. Rapport om rus og ruspolitikk 2008: Blå Kors Norge, 2008.

22. Statistic Norway. Health Interview Survey, survey of living conditions: Lifestyle habits, by sex and region. 2010 [2010-04-26]. Available from: http: //statbank.ssb.no//statistikkbanken/default_fr.asp?PLanguage=1.

23. Skutle A, Buvik K, Iversen E. 'Et glass vin etter jobben?”: Rusmiddelvaner i det kvinnedominerte arbeidslivet. Bergen: Stiftelsen Bergensklinikkene, AKAN kompetansesenter, 2009.

24. Wilhelmsen M. Samordnet levekårsundersøkelse 2008 - Tverrsnittsundersøkelsen: Dokumentasjonsrapport. Oslo: Statistic Norway - Statistisk Sentralbyrå, 2009. 